\title{
Teachers' Knowledge, Attitude and Practices of Inclusive Education in Nekemte Town and its Surrounding Government Primary Schools
}

\author{
Dessalegn Terfassa Moti $^{1}$, Adugna Bersissa Merdassa $^{2 *}$ and Kasech Tadesse Dessalegn ${ }^{2}$ \\ ${ }^{1}$ Nekemte College of Teachers' Education, Nekemte, Ethiopia \\ ${ }^{2}$ College of Education and Behavioral Sciences, Wollega University, P.O.Box.395, Nekemte, Ethiopia
}

\begin{tabular}{|c|c|}
\hline Abstract & Article Information \\
\hline $\begin{array}{l}\text { This study was conducted to investigate teachers' knowledge, attitude, and practices of } \\
\text { inclusive education in Nekemte town and its surrounding government primary schools; and } \\
\text { how their knowledge and attitude towards inclusion affect the practice of inclusive education. } \\
\text { The participants of the study were primary school teachers and principals. Equal numbers of } \\
\text { teachers were included into the study both from Nekemte town (62 teachers) and its } \\
\text { surrounding government primary schools ( } 62 \text { teachers). One principal from each school, } \\
\text { totally six principals were participated. Data was collected using a Likert type scale } \\
\text { questionnaire. Descriptive statistics, hierarchical multiple regression, and series of one way } \\
\text { MANOVA were used in the analysis. The result indicated that Primary school teachers had } \\
\text { slightly moderate knowledge about inclusive education and predominantly neutral attitude } \\
\text { towards inclusive education. The result also indicated that primary school teachers in the } \\
\text { study area rarely practice inclusive education. Knowledge of the teachers significantly } \\
\text { contributed to the practice of inclusive education, while attitude of teachers did not. No } \\
\text { statistically significant differences were found between teachers due to their sex, training, } \\
\text { teaching experience in their knowledge, attitude, and practices of inclusive education, while } \\
\text { statistically significant difference was observed between urban and rural primary school } \\
\text { teachers in their practices of inclusive education. Raising awareness of teachers about } \\
\text { inclusive education, the need to equip teachers with theoretical knowledge and practical skill } \\
\text { of inclusive education, and making school environment accessible are some of the } \\
\text { recommendations suggested. } \\
\text { Copyright@2016 STAR Journal, Wollega University. All Rights Reserved. }\end{array}$ & $\begin{array}{l}\text { Article History: } \\
\text { Received : 15-12-2015 } \\
\text { Revised : 04-03-2016 } \\
\text { Accepted : 19-03-2016 } \\
\text { Keywords: } \\
\text { Inclusive education } \\
\text { Teachers' attitude } \\
\text { Primary Schools } \\
\text { Knowledge } \\
\text { Practice } \\
\text { *Corresponding Author: } \\
\text { Adugna Bersissa } \\
\text { E-mail: } \\
\text { adugnaber@yahoo.com }\end{array}$ \\
\hline
\end{tabular}

\section{INTRODUCTION}

Education as basic human rights was enshrined in the 1948 Universal Declaration of Human Rights. This declaration states everyone has the right of equal access to public services in general and education in particular, and establishes the principle of free basic compulsory education for citizens to support the full development of human personality, and to strengthen respect for human rights and fundamental freedoms.

Currently, provision of education for all children regardless of any differences they have is one of the issues United Nations is working on. That is why Quality Education for All is one of the 8 Goals as stated in Millennium Development Goals. However, there are some groups who are excluded from this right. People with disabilities, orphans, children from impoverished areas are some of the excluded groups.

Inclusive education is not only about specific groups; it is also about the access and quality of education of all children. UNESCO (2005) views inclusion as presence, participation, and achievement of all students. According to Tirussew (1999), inclusive education is nothing more than just good school management, good teaching. It is a move towards schools that are structured around pupils' diversity and can accommodate many different ways of organizing pupils or learning to attain excellence in diversity.

Ethiopia has accepted international declarations and conventions of education, and states education as human rights. Years were spent since the country had been in the Education for All process; however, there is still a gap between theory and practice in providing access to all children and addressing each individual educational need in the classroom (MoE, 2006). The repetition rate and dropout rate for primary education is high (MoE, 2015). The gross enrollment rate of children with special needs in Ethiopia is only $3.4 \%$ (MoE, 2012).

The extent to which inclusive education is practiced depends on the degree of levels of teachers' attitude, and how schools conceptualize inclusive education. Dapudong (2014) found teachers' knowledge about inclusive education and attitude towards inclusion as a decisive factor to affect the process and practice of inclusion to a great extent. 
Dessalegn Terfassa Moti et al.,

Regarding attitude of teachers and students towards the integration and inclusion of students with different types of disabilities into regular classrooms, a great number of studies have been conducted in Ethiopia. For instance, Gezahegne and Yinebeb (2010), Tirussew (1999), Tirusew (2006) are some of them. The findings of research conducted at different times, on teachers' attitudes towards inclusion is not similar. According to Abate and Abebe; cited in Gezahegne and Yinebeb (2010), the majority of regular education teachers had a negative attitude towards inclusion. On the other hand, Tilahun cited in Gezahegne and Yinebeb (2010) revealed that the practices of inclusive education for the student with hearing impairment were found to be satisfactory. Etenesh cited in the same source found that most teachers reject the admission of students with disabilities into their schools. From the different sources stated and discussed above, children with disabilities are excluded from education. Besides to this, inability to address the individual need in the regular classroom resulted in wastage of education such as repetition, dropout, and low achievement (MoE, 2006). To understand and overcome the underlying problem, the study tried to make evidence based investigation on teachers' knowledge, attitude, and practices of inclusive education in the study area.

Perhaps, as part of the country, Nekemte town and its surrounding could not escape from the most intimidating challenges in implementing inclusive education and thereby achieving Quality Education for All. Therefore, the purpose of this study is to investigate the knowledge, attitude, and practices of teachers towards inclusive education; and how their knowledge and attitude towards inclusive education affects the practice of inclusive education.

\section{MATERIALS AND METHODS}

\section{Study Site}

The study was conducted at Nekemte town and its surrounding government primary schools in western Oromia, Ethiopia.

\section{Sampling Technique}

There were 23 schools in Nekemte town and its surrounding. From the twenty three schools, six schools (three from Nekemte town, and three from its surrounding) were selected by cluster random sampling. Accordingly, Bake Jama, Burka Bekumsa, and Dalo primary schools from Nekemte town; and Tinfa, Mulata, and Bekumsa Biya primary schools from surrounding Nekemte were selected. In both areas of the study, in the selected schools, there were 178 teachers. From these, 124 teachers were selected and participated in the study.
Sci. Technol. Arts Res. J., Jan-March 2016, 5(1): 102-107

\section{Data Gathering Instruments}

Data was collected using questionnaire. The questionnaire contains three scales. The attitude scale was adapted from Attitudes towards Inclusive Education Scale (ATIES) developed by Wilczenski (1992). It contains 28 items after adaptation. The items were structured on the basis of Likert's five point scale with 1= strongly disagree, $2=$ disagree, $3=$ neutral, $4=$ agree and $5=$ strongly agree. The reliability of the scale was found to be .89 Cronbach Alpha.

The questionnaire for the knowledge scale and practice scale were prepared by the researchers each having 12 and 17 items, respectively. The reliability of each scale was found to be .79 Cronbach alpha for the knowledge scale and .89 Cronbach Alpha for the practice scale. The items were structured on the basis of Likert's five point scale with $1=$ strongly disagree, $2=$ disagree, $3=$ neutral, $4=$ agree and 5= strongly agree.

\section{Statistical Data Analysis}

After data were collected, coded, and tabulated quantitative analyses were undertaken using SPSS (Statistical Package for the Social Sciences) version 20. Descriptive statistics, hierarchical multiple regression, and series of one way Multivariate Analysis of Variance (MANOVA) were used in the analysis. Descriptive statistics was used to determine the knowledge and attitude of teachers towards inclusive education; hierarchical multiple regression was used to see to what extent knowledge and attitude of teachers towards inclusive education predict the practice of inclusive education; and series of one way MANOVA were used to know whether there exist significant differences between the mean score of the two groups of sex (female and male), training (trained and not trained in special needs/inclusive education), place of work (urban and rural) among teaching experience of teachers (High, medium, low) at .05 significant level.

\section{RESULTS}

Demographic Characteristics of Participants

Table 1 presents summary of participants' background characteristics. The study consists of 124 participants, 62 participants from each study (urban and rural). Regarding sex of the respondents, 58(46.8\%) of the participants are male, while 66(53.2\%) are female. Concerning participants' training in special needs/inclusive education, $95(76.6 \%)$ are trained and $29(23.4 \%)$ are untrained. From those who have training, only 2 participants have specialization (one diploma holder, and the other $1^{\text {st }}$ degree) in special needs education while the rest have college or university three credit hour common course training.

Table 1: Summary of Demographic Characteristics of Participants

\begin{tabular}{llcc}
\hline & Variables & $\mathbf{N}$ & $\mathbf{\%}$ \\
\hline \multirow{2}{*}{ Place of work } & Urban & 62 & 50 \\
& Rural & 62 & 50 \\
\hline \multirow{2}{*}{ Sex } & Male & 58 & 46.8 \\
& Female & 66 & 53.2 \\
\hline \multirow{2}{*}{ Training in Special Needs/Inclusive Education } & Trained & 95 & 76.6 \\
& Untrained & 29 & 23.4 \\
\hline \multirow{3}{*}{ Teaching Experience } & $1-5$ & 22 & 17.7 \\
& $6-10$ & 24 & 19.4 \\
& 11 and above & 78 & 62.9 \\
\hline
\end{tabular}




\section{Descriptive Statistics of the Study Variables}

As indicated in table 2, the mean score of the participants on knowledge scale is 36.82 out of 60 or 3.06 out of 5 . This implies the knowledge of primary school teachers about inclusive education is slightly moderate. The table also presents the overall mean of participants on attitude scale is 86.91 out of 140 or 3.10 out of 5 , which shows the attitude of teachers towards inclusive education is moderately neutral. The mean score of teachers about inclusive education practices is 36.41 out of 85 or 2.14 out of 5 . This implies the practice of inclusive education is below average which shows teachers in the study area rarely practice inclusive education.

Table 2: Descriptive Statistics of the Study Variables

\begin{tabular}{lcccccc}
\hline Variable & No of Items & Minimum & Maximum & Mean & SD & N \\
\hline Knowledge & 12 & 13.00 & 56.00 & 36.82 & 7.19 & 124 \\
\hline Attitude & 28 & 35.00 & 134.00 & 86.91 & 18.06 & 124 \\
\hline Practice & 17 & 20.00 & 59.00 & 36.41 & 8.24 & 124 \\
\hline
\end{tabular}

Effects of Demographic and Independent Variables on Inclusive Education Practices

The association between the criterion variable (Inclusive education practices), and the predictor variables have been estimated using Pearson correlation coefficient. Table 3 presents the correlation coefficient between and among variables.

In the correlation analysis, the association between the dependent variable and independent variables has been estimated. Hence, some demographic variables (sex, teaching experience, and training in special needs) did not show statistically significant relationship with inclusive education practices, while place of work $(r=-.31, P<0.05)$, knowledge $(r=0.37, P<0.05)$, and attitude, $\quad(r=0.31$, $P<0.05)$ were significantly associated with inclusive education practices.

\section{Prediction of Inclusive Education Practices}

To determine the combined effects of the independent variables on the dependent variable, hierarchical multiple regression model was used. Thus, in the regression estimation for dependent variable, six predictor variables which were thought to affect practices of inclusive education were included in the model.

In the regression model, there were two models listed. Model 1 refers to the first block of variables that were entered (experience, sex, training, and place of work), while model 2 includes all the variables that were entered (experience, sex, training, place of work, knowledge, and attitude).

As it can be seen from Table 4, after the variables in Block 1 (experience, sex, training, and place of work) have been entered, the overall model explains $11.1 \%$ of the variance. After Block 2, knowledge and attitude variables have also been included, then the model as a whole explains $22.9 \%$. It is important to note that this second $\mathrm{R}$ square value includes all the variables from both blocks, not just those included in the second step.

Table 3: Inter-Correlations among Variables of Interests

\begin{tabular}{|c|c|c|c|c|c|c|c|}
\hline & Sex & $\begin{array}{c}\text { Place of } \\
\text { Work }\end{array}$ & $\begin{array}{c}\text { Teaching } \\
\text { Experience }\end{array}$ & $\begin{array}{c}\text { Training in } \\
\text { Special Needs }\end{array}$ & Knowledge & Attitude & Practice \\
\hline Sex & 1 & & & & & & \\
\hline Place of work & -.129 & 1 & & & & & \\
\hline Teaching experience & -.076 & $-.291^{*}$ & 1 & & & & \\
\hline Training in special needs & $-.208^{\star}$ & -.057 & $.218^{\star}$ & 1 & & & \\
\hline Knowledge & -.054 & -.069 & .040 & -.103 & 1 & & \\
\hline Attitude & -.084 & -.150 & .067 & -.103 & $.553^{\star}$ & 1 & \\
\hline Practice & -.028 & $-.306^{\star}$ & .049 & -.076 & $.369 *$ & $.305^{\star}$ & 1 \\
\hline
\end{tabular}

Table 4: Hierarchical Multiple Regression Analysis

\begin{tabular}{|c|c|c|c|c|c|c|c|c|}
\hline Variables in the model & Model 1 & & & & Model 2 & & & \\
\hline & B & SE & $\beta$ & $t$ & B & SE & $\beta$ & $\mathbf{t}$ \\
\hline Practice & 50.066 & 4.665 & & $10.732^{*}$ & 31.254 & 6.407 & & $4.878^{\star}$ \\
\hline Experience & -.024 & .069 & -.032 & -.345 & -.036 & .065 & -.047 & -.545 \\
\hline Sex & -1.577 & 1.472 & -.096 & -1.072 & -.955 & 1.395 & -.058 & -.685 \\
\hline Training & -2.103 & 1.750 & -.109 & -1.202 & -1.082 & 1.644 & -.056 & -.650 \\
\hline Place of work & -5.474 & 1.501 & -.334 & $-3.646^{\star}$ & -4.864 & 1.428 & -.297 & $-3.406^{\star}$ \\
\hline Knowledge & & & & & .332 & .112 & .290 & $2.973^{*}$ \\
\hline Attitude & & & & & .042 & .045 & .092 & .932 \\
\hline$\left(\mathbf{R}^{2}\right),\left(\right.$ Adjusted $\mathbf{R}^{2)}$ & \multicolumn{4}{|c|}{ (.111), (.082) } & \multicolumn{4}{|c|}{$.229, .190$} \\
\hline (R square change), (F change) & \multicolumn{4}{|c|}{ (.111), $\left(3.732^{\star}\right)$} & \multicolumn{4}{|c|}{$.118,8.946^{*}$} \\
\hline $\mathbf{F}$ & \multicolumn{4}{|c|}{$\left[F(4,119)=3.732^{*}\right.$} & \multicolumn{4}{|c|}{$\left[F(6,117)=5.802^{*}\right.$} \\
\hline
\end{tabular}




\section{Dessalegn Terfassa Moti et al.,}

To find out how much of this overall variance is explained by our variables of interest (knowledge and attitude) after the effects of demographic variables are removed, we need to look at $\mathrm{R}$ square change. When we see on the line marked Model 2, the $\mathrm{R}$ square change value is .118. This means knowledge and attitude explain an additional $11.8 \%$ of the variance in inclusive education practices, even when the effects of demographic variables are statistically controlled for. This is a statistically significant contribution, as indicated by the sig. $\mathrm{F}$ change value for this line (.000). The ANOVA table indicates that the model as a whole (which includes both blocks of variables) is significant $[F(6,117)=5.802, P<.05)$. There are only two variables that make a statistically significant contribution. In order of importance they are: Place of work $(\beta=-3.41)$ and knowledge $(\beta=2.97)$. The rest variables did not make a unique contribution.

\section{Multivariate Analysis of Variance Results}

Series of one way multivariate analysis of variance (MANOVA) were conducted to examine the effect of sex place of work, teaching experience, and training in special needs/inclusive education on dependent variables (knowledge, attitude, and practice of inclusive education).

As indicated in table 5 , there is statistically significant difference on the combined dependent variables between urban and rural, Wilks' $\lambda=.895, F(3.000,120.000)=$ $4.692, P=.004$, partial eta squared $=.105(10.5 \%)$ of the portion of the variance in the dependent variable that can be explained by the independent variable (place of work); however, there was no statistically significant difference between males and females, Wilks' $\lambda=.993, F(3.000$, $120.000)=.285, \quad P=.836$, partial eta squared $=.007$; between trained and untrained in special needs/inclusive education, Wilks' $\lambda=.985, \quad F(3.000,120.000)=.603, \quad P$ $=.614$, partial eta squared $=.015 ;$ among teaching experience categories, Wilks' $\lambda=.974, F(6.000,238.000)$ $=.520, \mathrm{P}=.793$, partial eta squared $=.013$.

The significant result on the multivariate test of significance leads us to investigate further tests in relation
Sci. Technol. Arts Res. J., Jan-March 2016, 5(1): 102-107

to each of the dependent variables. When looking at a number of separate analyses here, it is suggested that it is necessary to set a higher alpha level to reduce the chance of a Type I error. The most common way of doing this is to apply what is known as a Bonferroni adjustment (Tabachnick and Fidell, 2001). This involves dividing the original alpha level of .05 by the number of analyses that is intended to do. In this particular case, there are three dependent variables to investigate; therefore we would divide .05 by 3 , giving a new alpha level of .017 .

Table 5: Results of Multivariate Tests

\begin{tabular}{lcccc}
\hline \multicolumn{1}{c}{ Effect } & $\begin{array}{c}\text { Wilks' } \\
\text { Lambda }\end{array}$ & F & P & $\begin{array}{c}\text { Partial } \\
\text { Eta Squared }\end{array}$ \\
\hline Sex & .993 & .285 & .836 & .007 \\
Place of work & .895 & 4.692 & $.004^{*}$ & .105 \\
Experience & .974 & .520 & .793 & .013 \\
Training & .985 & .603 & .614 & .015 \\
\hline \multicolumn{4}{l}{ * Significant at .05 level. }
\end{tabular}

Table 6 presents when the results for the dependent variables were considered separately, the only difference to reach statistical significance, using Boneferroni adjusted alpha level of .017 was practice of inclusive education $F(1,122)=12.584, P=.001$, partial eta squared $=.094$. We can understand from the table that only one of the dependent variables (practice) recorded a significance value less than our cut - off (with a sig. value of .001). In this study, the only significant difference between urban and rural was on practice of inclusive education scores.

Although we know that urban and rural differed in terms of practice of inclusive education, we do not know who had the higher scores. But an examination of the mean scores revealed that urban scored significantly higher on practice of inclusive education ( $\mathrm{M}=38.919$, SD $=8.93198)$ than rural $(M=33.903, S D=6.64735)$. This means, urban teachers were found to practice inclusive education more frequently than rural teachers.

Table 6: Tests of between- subjects Effects

\begin{tabular}{cccccccc}
\hline Source & $\begin{array}{c}\text { Dependent } \\
\text { Variable }\end{array}$ & $\begin{array}{c}\text { Type III Sum } \\
\text { of Squares }\end{array}$ & Df & $\begin{array}{c}\text { Mean } \\
\text { Square }\end{array}$ & F & Sig. & $\begin{array}{c}\text { Partial } \\
\text { Eta Squared }\end{array}$ \\
\hline \multirow{3}{*}{$\begin{array}{l}\text { Place of } \\
\text { Work }\end{array}$} & Attitude & 905.040 & 1 & 905.040 & 2.816 & .096 & .023 \\
& Knowledge & 30.008 & 1 & 30.008 & .578 & .448 & .005 \\
& Practice & 780.008 & 1 & 780.008 & 12.584 & $.001^{*}$ & .094 \\
\hline \multicolumn{7}{c}{ * Significant at .017 level }
\end{tabular}

\section{DISCUSSIONS}

The general objective of this study was to investigate the level of knowledge, and attitude of teachers towards inclusive education, and what practices are there in implementation of inclusive education in primary schools of the study area. The descriptive statistics of this study revealed that respondents' mean scores on both knowledge and attitude were slightly above average. The mean score of the respondents on practice of inclusive education was below average. That means teachers in the study area rarely practice inclusive education.

Similar to this finding, MoE (2012) stated unawareness of the universal right to primary education and lack of knowledge about inclusive education of school management and teachers resulted in exclusion of a significant number of children from all education and lack of provision of quality education. This limited knowledge and moderate attitudinal problem resulting in rare practice of inclusive education could emanate from the infancy stage of inclusive education in Ethiopian context and needs to work on

The study attempted to investigate the extent of knowledge of primary school teachers about inclusive education. The descriptive data analysis of this study revealed that primary school teachers' knowledge about inclusive education was slightly moderate. 
Similar to the finding of the present study, Dapudong (2014) reported that teachers have moderate knowledge on inclusive education. Belapurkar (2012) found school teachers are not clear about the concept of inclusive education. Similar to this source, Afreen (2011) identified secondary school teachers have insufficient knowledge on inclusive education.

This study tried to investigate the level of attitude of primary school teachers towards inclusive education. The mean score of the respondents on attitude scale was 3.1 out of 5 or 86.91 out of 140 . This shows primary school teachers have moderately neutral attitude towards inclusive education.

Inconsistent with this finding, Dapudong (2014) found that teachers have a neutral level of attitude towards including children with special educational needs in regular classrooms in terms of their feelings or expected outcomes of inclusion. Alghazo and Naggar cited in Afreen (2011) reported similar finding. They found that teachers had neutral attitudes towards pupils with behavioral difficulties in regular classrooms.

Different sources reported in contrast to this finding. According to Abate and Abebe cited in Gezahegn and Yinebeb (2010), the majority of regular education teachers had a negative attitude towards inclusion. Etenesh cited in the same source found that most teachers reject the admission of students with disabilities into their schools. Similarly, the study conducted on primary school teachers' views in Botswana revealed that teachers did not have favorable attitude towards inclusive education. These regular teachers were of the opinion that such learners lacked the skills needed to master the regular classroom curriculum. This finding was consistent with recent literature that established whilst teachers were positive about inclusive education, they preferred to include certain categories of learners with special educational needs rather than others (Bawa and Mangope, 2011; Chhabra, Srivastva and Srivastva, 2009; Parsuram, 2006; Rafferty and Griffin, 2005) cited in (Mukhopadhya, 2013). A number of studies investigating teachers' attitude towards inclusive education further indicated teachers' negative attitude towards inclusive education in contrast to the present finding. For instance, findings revealed from the study of Gill and Sherman cited in Malak (2013) indicate that pre-service teachers became progressively more negative towards including students with special educational need in regular classrooms.

The present study examined the combined effects of knowledge and attitude towards inclusive education on the practice of inclusive education. Hierarchical multiple regression was used for this analysis. It was found that knowledge and attitude explain an additional $11.8 \%$ of the variance in inclusive education practices, showing the extent of prediction of knowledge and attitude towards inclusive education on the practices of inclusive education. This finding is consistent with Ross-Hill cited in Malak (2013). According to this source, the success and failure of education depends on the knowledge and attitudes and responses that teachers exhibit in classrooms. Ajzen cited in Malak (2013) also revealed that the attitude of teachers influence their behavior in classrooms. Ryam cited in the same source indicated teachers' knowledge of diverse learning needs influences their feelings and overall behaviors towards students with special educational needs. Therefore, the attitude of teachers towards inclusive education and their knowledge about inclusive education matters the practice of inclusive education. This is because the general view someone has about something and the concept of that person about that thing determines the practical implementation expected of that individual.

The present study further revealed that teachers' knowledge about inclusive education made statistically significant contribution to the practice of inclusive education, while attitude did not make a unique contribution. In line with this finding, USAID (2011) identified having a clear understanding of inclusive education is important because "different underlying principles and values can produce very different outcomes." Inclusive education will fail or be unsustainable when there is a limited knowledge about it. For instance, if we take a child as the centre of the problem and try to develop and monitor programs or practice intervention, we definitely become unsuccessful because having different underlying principles and values will help us to challenge different problems and ultimately produce very different outcomes. Accordingly, misconceptions and objections disappear when the underlying concepts of inclusive education are thoroughly understood.

The present study also compared urban and rural teachers to determine if there are significant differences in their knowledge about inclusive education, attitude towards inclusive education, and practices of inclusive education. The results revealed that place of work was significant only for practice of inclusive education. Urban teachers were found to practice inclusive education more frequently than rural teachers. This finding is consistent with previous studies. Mamo (2001), Tirussew et al. (1995) and Tirussew (2006) cited in MoE (2006) indicated the existing special units, schools, resource rooms, and trained teachers are located in urban areas. Consequently, a significant number of children are still excluded from all education. This shows inclusive education is being practiced slightly in urban areas than the rural ones.

\section{CONCLUSIONS}

The mean scores of the respondents on both knowledge and attitude were slightly above average, while that of the practice of inclusive education was below average. The knowledge of primary school teachers about inclusive education was slightly moderate. The attitude of primary school teachers towards inclusive education was moderately neutral. Both knowledge about inclusive education, and attitude towards inclusive education were correlated positively with practices of inclusive education and explained an additional $11.8 \%$ of the variance in inclusive education practices; knowledge making statistically significant contribution to the practice of inclusive education, while attitude did not make a unique contribution. There were no statistically significant differences found between male and female, trained and untrained in special needs/inclusive education, teaching experience in their knowledge, attitude, and practices of inclusive education, while statistical significant difference was observed between urban and rural primary school teachers in their practices of inclusive education. 
Dessalegn Terfassa Moti et al.,

\section{Conflict of Interest}

None declared.

\section{REFERENCES}

Afreen, T.K. (2011). Investigation of secondary school teachers' attitudes towards and knowledge about inclusive education in Bangladesh. University of Canterbury. Masters of Education Thesis. http://library.canterbury.ac.nz/thesis/etheses copyright.sh $\underline{\mathrm{tml}}$

Belapurkar, A.M. (2012). Knowledge and attitude about inclusive education of school teachers. Pune: H.G.M.

Dapudong, R.C. (2014). Teachers' knowledge and attitude towards inclusive education: Basis for an enhanced professional development program. International Journal of Learning and Development 4(4):1-24.

Gezahegne, B. and Yinebeb, T. (2010). Attitude of teachers towards inclusive education in Ethiopia. Ethiopian Journal of Education 6(1): 89-96.

Malak, S. (2013). Inclusive education reform in Bangladesh: Pre-service teachers' responsesto include students with special educational needs in regular classrooms. Dacca: University of Dhaka.

MOE (2006). Special needs/inclusive education program strategy. Addis Ababa: MoE.

MOE (2012). Special needs/inclusive education program strategy. Addis Ababa: MoE.

MOE (2012). Special needs/inclusive education program strategy implementation guideline. Addis Ababa: MoE.
Sci. Technol. Arts Res. J., Jan-March 2016, 5(1): 102-107

MoE (2015). Education statistics annual abstract. Addis Ababa: MoE.

Mukhopadhyay, S. (2013). Voices of experience: Botswana primary schools teachers on inclusive education. European Journal of Education Studies 5(1): 73-85.

Tabachnick, B. G. and Fidell, L.S. (2001). Using multivariate statistics (4th edn). New York: Harper Collins.

Tirussew, T. (1999). Inclusion of children with disabilities in regular schools. Challenges and opportunities. The Ethiopian Journal of Education XIX(1): 29-58.

Tirussew, T. (2006). An overview of inclusive development in the last fifteen years in Ethiopia. In: eds. H.Salvolainen, M. Matero and $\mathrm{H}$. Kokkal. When All means All: Experiences in three African countries with EFA and children with disabilities, Hakapain oy, Helsinki, Finland.

UNESCO. (1948). Universal Declaration of Human Rights: Access to education for all. Paris: UNESCO.

UNESCO. (2005). Guidelines for inclusion: Ensuring access to education for all. Paris: UNESCO.

USAID/IQPEP. (2011). Special needs education and inclusive education: A module developed for capacity building of college of teachers education instructors in Ethiopia.

Wilczenski, F. L. (1992). Development of a scale to measure attitude toward inclusive education. Educational and Psychological Measurement 55(2): 291-299. 